\title{
Calculation of Radiation Dose Received by Patients during Cardiac Interventional Procedure
}

\author{
Abdoelrahman Hassan A. B ${ }^{1,2,3}$, M. E. M. Gar-elnabi, Eitidal H. Khalafalla ${ }^{1}$, F. I. Habani \\ ${ }^{1}$ Sudan University of Science and Technology, COMRS, Khartoum, Sudan \\ ${ }^{2}$ Anatalya Diagnostic Medical Center, Khartoum, Sudan \\ ${ }^{3}$ Elnielain Diagnostic Center, Khartoum, Sudan
}

\begin{abstract}
The process of interventional procedure can be associated with multilevel of radiation doses; the current study intends to measure patient dose and estimate the radiation dose received for patient during interventional cardiology (IC) procedures. In order to match the acceptable level, A 206 patients underwent IC procedure and the radiation dose were measured in Khartoum state hospitals, Sudan; in four types of (IC) procedures which are (CA, PCI, PTMC and pacemaker) the number patients for each procedure was 145 , 39,4 and 18 respectively. The mean age of patients was 59.9 \pm 14.1 which ranged from 3 to 100 years. The mean value of tube parameter was $78.2 \pm 11.4 \mathrm{KVp}$, (ranged from 50 to $109 \mathrm{Kvp}$ ), $7.1 \pm 0.72 \mathrm{mAs}$ (ranged from 3 to $10.2 \mathrm{mAs}$ ). The mean time of fluoroscopy exposure that was used during these procedure was 6.9 7.1 mint. Dosimetric quantity, called KERMA Area Product (KAP), and fluoroscopy time were registered during four selected procedures. For CA, PCI, PTMC and pacemaker the mean and median KAP values demonstrated as higher and lower values were found to be $\left(63.69,52 \mathrm{Gy. \textrm {cm } ^ { 2 } )}\left(18.78,15.5 \mathrm{~Gy}_{\mathrm{cm}} \mathrm{cm}^{2}\right)\right.$ for PCI and pacemaker respectively. The higher mean and median fluoroscopy time in minutes $(11.43,9.70)$ as registered for PCI procedure was reported in this study which may considered relatively higher value than reported in the literature.
\end{abstract}

Keywords: pacemaker, interventional radiology, radiation dose and KAP.

\section{Introduction}

Interventional cardiology are one of the subspecialty of interventional radiology, Interventional cardiology (IC) which involves coronary angiography (CA) diagnostic procedures and percutaneous coronary interventions (PCI) therapeutic procedures is becoming progressively more common, Patient dosimetry in IR and IC is extremely in which the highest patient doses are imparted with the use of fluoroscopy X-ray techniques in diagnostic or therapeutic procedures [1]. Clinical patient benefit usually compensates radiological risk; however, there is agreement among experts about the need for measuring patient doses routinely and the urgency of setting up optimization procedures [2]. The number of interventional procedures, dedicated radiological installations and centers applying those interventions increases continuously. Technical improvements in the design of dedicated digital procedures are progressing. Nowadays, medical specialists are able to choose the image quality level they wish for each procedure. Improving image quality is usually associated with higher patient and staff doses. Unfortunately, most IR equipment in use does not incorporate the dose measuring devices. The benefits from interventional cardiology (IC) procedures are well understood when compared with traditional surgery which is considered as more invasive procedure. In general, IC considered as less invasive, typically of less pain and risk to patients; in addition to that patient recovery time is much less. However, it is related with high patient and staff radiation doses. The values of dose-area product and effective dose for interventional radiology (IR) are typically larger than those used in common diagnostic X-ray examinations. According to UNSCEAR (3) from 1992 to 1995 in the USA, there were 26 reports to the Food and Drug
Administration (FDA) of radiation- induced skin injuries from fluoroscopy. In 1999, the FDA documented some 50 cases of radiation-induced burns, many patient are underwent IC procedures. Reports from the FDA's voluntary registry and other worldwide studies are continuing to detect more incidents of skin burn following IC $(4,5)$. Justification and optimization in IR are highly required by the international standards $(6,7)$. Special attention should be given to the quality assurance programs, including quality control measures and patient-dose assessment in IR (8). Cardiac interventional procedures growing better now in Sudan where 2 hospital where introduced IC in but rapidly increased to be more than 9 hospitals at the time of this study. Studies on patient and staff in interventional procedures in Sudan are very limited. Therefore the main objectives of this study was to measure the dose receive by the patient and to evaluate the level of radiation dose to patient during interventional cardiac catheterization procedure.

\section{Material and Method}

Patient radiation dose measurement during cardiac catheterization were made using KERMA area product (KAP) meter which attached to the $\mathrm{C}$-arm machine. This study was conducted at Khartoum state hospitals in period from 2014 to December 2015 for 206 patients. All the patients were adults with age $>15$ years except three patients their age $<5$ years, 145 underwent coronary angiography (CA), 39 with percutaneous coronary interventions (PCI) 4 percutaneous Trans venous mitral Commissurotomy (PTMC) and 18 to pacemaker. The following parameter was recorded such as patient body characteristic (age, weight, height (BMI), clinical indication, sex and type of procedures). In all procedures dosimetric quantity, namely KERMA area 


\section{International Journal of Science and Research (IJSR) \\ ISSN (Online): 2319-7064 \\ Index Copernicus Value (2013): 6.14 | Impact Factor (2014): 5.611}

product was evaluated using KAP meter from the C- arm machine. The patient dose categorized according to the types of procedures, patient body characteristic.

X-ray system that used to perform this types of intervention was conducted using C-arm ((Philips- Integris (Philips Medical System Cooperation, Hamburg, Germany)) serial number is 236781 , normal voltage $125 \mathrm{KV}$ and permanent filtration $2.5 \mathrm{AL} / 75$, the system was Manufacturing and installed in 2012. Selected procedures: The most common performed cardiac procedures in the hospital were selected, namely $\mathrm{CA}$, for the examination of blood vessels or chambers of the heart, PTCA; for treating the stenotic coronary arteries of the heart, Percutaneous Trans venous Mitral Commissurotomy (PTMC) which is carried out when a mitral valve becomes narrowed. It is a long-term complication of rheumatic fever. While rheumatic fever is becoming rare in the developed western world, in developing countries it is still a major health issue. The last procedure was the implantation of an artificial pacemaker by physicians to correct a slow heart.

\section{Result}

Table 1: Statistical summary of Patient body characteristics and Tube parameters in radiologic procedure (Mean \pm SD)

\begin{tabular}{|c|c|c|c|c|}
\hline \multirow{2}{*}{ Variable } & \multicolumn{4}{|c|}{ Mean \pm SD } \\
\cline { 2 - 5 } & CA & PCI & Pacemaker & PTMC \\
\hline Age & $59.9 \pm 2.8$ & $58.6 \pm 17$ & $62.7 \pm 19.8$ & $49.5 \pm 15.7$ \\
\hline Weight & $76.5 \pm 27$ & $73.9 \pm 16$ & $69.7 \pm 22.9$ & $66.0 \pm 16.1$ \\
\hline Height & $159 \pm 11$ & $167.3 \pm 14$ & $161.8 \pm 20$ & $167.5 \pm 12$ \\
\hline BMI & $20.5 \pm 3.3$ & $26.3 \pm 5.3$ & $25.8 \pm 6.6$ & $23.3 \pm 4.3$ \\
\hline Kvp & $92.0 \pm 5.7$ & $80.7 \pm 15$ & $80.5 \pm 18.5$ & $73.5 \pm 11.7$ \\
\hline mAs & $8.5 \pm 0.7$ & $7.2 \pm 1.2$ & $6.9 \pm 0.7$ & $6.5 \pm 0.6$ \\
\hline SSD & $110 \pm 0.7$ & $105.3 \pm 7$ & $105.8 \pm 6.1$ & $108.5 \pm 4.4$ \\
\hline Gycm ${ }^{2}$ & $29.5 \pm 40$ & $63.7 \pm 49$ & $18.8 \pm 16.3$ & $25.3 \pm 31.7$ \\
\hline Time $(\mathrm{m})$ & $3.15 \pm 1.6$ & $11.4 \pm 6.7$ & $5.7 \pm 3.2$ & $9.6 \pm 11.5$ \\
\hline
\end{tabular}

$\begin{array}{llllll}86 & & & & \\ 0 \\ 01\end{array}$

Figure 1: Demonstrate the linear correlation between the Kvp and the BMI.

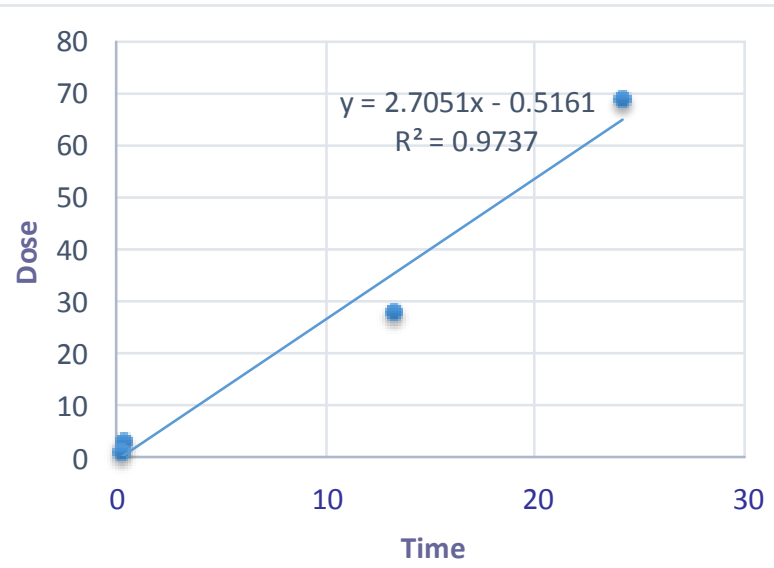

Figure 2: showed linear relationship between the Gy. $\mathrm{cm}^{2}$ and fluoroscopic time with $\mathrm{R} 2=0.9737$ during PTMC procedures.

Table 2: Correlation coefficients for KAP with T (time) and BMI.

\begin{tabular}{|c|c|c|}
\hline \multirow[t]{2}{*}{ Procedure } & \multicolumn{2}{|l|}{ DAP } \\
\hline & $\mathrm{T}$ & BMI \\
\hline $\mathrm{CA}$ & 0.023 & 0.022 \\
\hline PCI & 0.483 & 0.094 \\
\hline PTMC & 0.974 & 0.414 \\
\hline Pacemaker & 0.097 & 0.012 \\
\hline
\end{tabular}

\section{Discussion}

The patients with their demographic data including, mean, standard deviation, for (age, height, weight and body mass) and tube parameters (Kvp, mAs, SSD, DAP and fluoroscopy time) listed in Table (1) for each procedure.

Correlation of these parameters with radiation dose where evaluated the majority were significant but the radiation dose are strongly associated with fluoroscopic time in which the dose increased by $2.7051 \mathrm{~Gy} . \mathrm{cm}^{2}$ for every one mint increment in exposure time, $R=0.9737, Y=2.7051 X-0.51$.

The highest KAP related to PCI possibly due to longer time associated with this procedure which having a mean of $(11.4 \pm 6.7 \mathrm{~min})$. The lowest KAP related to Pacemaker because in this procedure used the fluoroscopy more than cine graphic.

KAP values for CA and PTMC procedures were found to be $(29.50 \pm 40.31)$ and $(25.25 \pm 31.65)$ respectively. The total Mean fluoroscopy time in minutes for the three procedures was 9.6, 6.6 and 3.15 for PTMC, pacemaker and CA, respectively. A linear correlation between the Kvp and BMI in direct relationship noted with significant association which increased by $0.280 \mathrm{~kg} / \mathrm{m}^{2}$ for every one $\mathrm{Kvp}$ increment in tube voltage when the mean value of Kvp where equal to $92.00 \pm 5.66$ with $\mathrm{R} 2=0.026$, and the linear regression equation that can describe this correlation was $y=0.2798 x+$ 69.834 during CA procedures. This was compared with the relation in PCI, Pacemaker and PTMC procedures when the mean value of BMI and Kvp was 26.26 \pm 5.26 and 


\section{International Journal of Science and Research (IJSR) \\ ISSN (Online): 2319-7064}

Index Copernicus Value (2013): 6.14 | Impact Factor (2014): 5.611

$80.67 \pm 15.11,23.38 \pm 4.26$ and $73.50 \pm 11.68,25.80 \pm 6.64$ and $80.50 \pm 18.51$, respectively. In more strong correlation that PTMC where the R2 $=0.9301$, as showed in figure (1).

Time, distance and shielding considered the three main ways to protect the worker and the staff during and radiological procedure and investing action also the patient (minimum time, far distance and maximum shielding with minimum radiation dose) here because we using the fluoroscopic operation the catheterization procedure so more time and more radiation used.

In order to optimize the procedures in this catheterization laboratory it is important to understand the relation between the different factors and dose indicators in each case, and which factors have significant influence on patient dose. For that purpose, the correlation between KAP and T (time) as well as KAP with BMI was derived as listed in Table 2. Good correlation was found between T and DAP in PTMC with linear correlation factor of 0.974 , poor correlation was observed in CA, PCI and Pacemaker which meant that time was not necessarily a good indicator of higher DAP. Procedures could be performed in shorter time but with an increased number of frames and vice versa. It is suggested that the difference in the number of cine-graphic frames used is the explanation for that. Betsou et al. (8) have shown that radiation dose from cine graphic mode frames contribute $60 \%$ of the total dose in diagnostic procedures. Table 2 also includes the correlation factors values for KAP with BMI. As can be seen there was weak correlation for CA, PCI, PTMC and pacemaker, which means that BMI is not an indicator for dose in the procedures. It is possible that differences in diseased vessels' location and type and complexity of disease from patient to patient have more influence on KAP than BMI. However, overweight will most likely lead to a higher dose when a complex procedure is performed. The increase of KAP with BMI in PTMC might be attributed to the use of mainly the right anterior oblique projection in PTMC, as changing in beam angulations will considerably change exposure factors owing to the increased or decreased volume exposed. The outcome of this study was compared with some published surveys for CA, PCI and pacemaker our mean KAP results for CA and PCI were lower than all other presented studies (9-12). It were found to be only higher than the values presented for Nada A. Ahmed et al. (21) and garelnabi et al (22).

The comparison of the present study with the suggested DRL guidelines has shown that doses for CA and PCI procedures in this hospital were in good agreement with the recommended levels with exception to PCI fluoroscopy time. However, and as the ALARA (as low as reasonably achievable) principle necessitates optimization of radiation protection, it is recommended to reduce patient doses while maintaining image quality and ensuring that optimized levels are consistent. The PCI procedure in this hospital is mostly required to be optimized as it is in general associated with higher radiation dose and it was linked with higher fluoroscopy time at the present study than in the other studies. And as it is well known that patient dose will build up with time; the potential for dose saving could be obtained by reducing the procedure time.
To optimize radiation protection, every effort should be made to reduce the KAP of a procedure and thus the effective dose to the patients. This goal can be primarily achieved in this hospital by: (1) intensive training of the operators, nurses and technologists (2) shift to lower cine-graphic modes and use less cine-graphic runs, (3) ) Use low-level fluoroscopy mode whenever possible, (4) position to the region of interest only and (5) reduce the fluoroscopy time as possible, (6) Avoid unnecessary magnification, (7) Apply the "as low as reasonably achievable" (ALARA) principle in emergency cases after gaining sufficient reperfusion.

\section{Conclusion}

In this study, patient doses were measured for IC procedures in a major cardiology hospital in Sudan and results were compared with other studies worldwide. No safe dose exists and we must assume that there is a need for improvement in the practice of radiation protection. Practical recommendations for potential optimization had been pointed out. It is recommended to expand this survey to include other hospitals and to use the results to raise the awareness of interventional cardiologists and radiographers on factors affecting patient dose and encourage them to undertake maximal efforts to reduce radiation exposure to the patients and themselves

\section{References}

[1] US Food \& Drug Administration. Avoidance of 8 serious X-ray induced skin injuries to patients during fluoroscopically guided procedures. Med Bull 1994;24:7-17

[2] National Radiological Protection Board. National Protocol for Patient Dose Measurements Diagnostic Radiology. Chilton: NRPB, 1992.

[3] UNSCEAR. Sources and effects of ionizing radiation. United Nations Scientific Committee on the Effects of Atomic Radiation Report to the General Assembly with Scientific Annexes. (United Nations) (2000).

[4] Vaño ', E., Arranz, L., Sastre, J. M., Moro, C., Ledo, A., Garate, M. T. and Mi 'nguez, I. Dosimetric and radiation protection considerations for some cases of patient skin injuries in interventional cardiology. Br. J. Radiol. 71, 510-516 (1998).

[5] Sovik, E., Klow, N. E., Hellesnes, J. and Lykke, J. Radiation-induced skin injury after percutaneous transluminal, coronary angioplasty. Case report. Acta Radiol. 37, 305-306 (1996).

[6] European Atomic Energy Community, Food and Agriculture Organization of the United Nations, International Atomic Energy Agency, International Labour Organization, International Maritime Organization, OECD Nuclear Energy Agency, Pan American Health Organization, United Nations Environment Programme, World Health Organization. Fundamental safety principles; safety fundamentals. IAEA Safety Standards Series No.sf-1. (IAEA) (2006).

[7] Food and Agriculture Organization of the United Nations, International Atomic Energy Agency, International Labour Organization, OECD Nuclear 


\section{International Journal of Science and Research (IJSR) \\ ISSN (Online): 2319-7064}

Index Copernicus Value (2013): 6.14 | Impact Factor (2014): 5.611

Energy Agency, Pan American Health Organization, World Health Organization. International Basic Safety Standards for protection against ionizing radiation and for the safety of radiation sources. Safety Series No.115. (IAEA) (1996).

[8] European Union, Council Directive 97/43/ EURATOM of 30 June 1997. Health protection of individuals against the dangers of ionizing radiation in relation to medical exposure (repealing Directive 84466EURATOM, O.J. No L 2651, 5.10.1984). Official J. Eur. Communities L180, 22-27 (1997).

[9] Vano, E., Gonzalez, L., Fernandez, J. M. and Guibelalde, E. Patient dose values in interventional radiology. Br. J. Radiol. 68, 1215-1220 (1995).

[10] Bakalyar D, Castellani MD, Safian RD. Radiation exposure to patients undergoing diagnostic and interventional cardiac catheterization procedures. Cather Cardiovascular Diagn 1997; 42: 121-5.

[11]Zorzetto M, Bernardi G, Morocutti G, Fontanelli A. Radia- tion exposure to patients and operators during diagnostic ca- theterization and coronary angioplasty. Cathet Cardiovasc Diagn 1997; 40: 348-51.

[12] Van de Putte S, Verhaegen F, Taeymans Y, Thierens H. Cor- relation of patient skin dose in cardiac interventional radiology with dose-area product. $\mathrm{Br} \mathrm{J}$ Radiol 2000; 73: 504-13.

[13] Hart, D., Hillier, M. C. and Wall, B. F. Doses to patients from medical X-ray examinations in the UK. 2000 Review, NRPB-W14. (HMSO) (2000).

[14]Hansson, B. and Karambatsakidou, A. Relationships between entrance skin dose, effective dose and dose area product for patients in diagnostic and interventional cardiac procedures. Radiat.Prot. Dosimetry. 90 (1-2), 141-144 (2000).

[15]Kuon, E., Glaser, C. and Dahm, J. B. Effective techniques for reduction of radiation dosage to patients under- going invasive cardiac procedures. $\mathrm{Br}$. J. Radiol.76, 406-413 (2003).

[16] Tsapaki, V., Kottou, S., Vano, E., Faulkner, K., Giannouleas, J., Padovani, R., Kyrozi, E., Koutelou, M., Vardalaki, E. and Neofotistou, V. Patient dose values in a dedicated Greek cardiac centre. Br. J. Radiol. 76 (910), 726-730 (2003).

[17] Efstathopoulos EP, Karvouni E, Kottou S, Tzanalardiou E, Korovesis S, Giazitzoglou E, et al. Patient dosimetry during coronary interventions: a comprehensive analysis. Am Heart J 2004; 147:468-75

[18] A.Trianni1,2,R. Padovani1, C .Foti1, E. Caranolini3,H. Toh3, G. Bernardi3 and A. proclemer3 .Dose to cardiologists in Hemodynamic and electrophysiology cardiac interventional procedures .Radiation Protection Dosimetry, 2005 : Vol 117, NO.1-3 pp 111-115.

[19] Padovani, R. et al. Reference level at European level for cardiac interventional procedure. Radiat. Prot. Dosimetry. 129(1-3), 104-107 (2008).

[20] Andreasi. stratis1, prodromosl. anjhopoulos2, isidorosp. gavaliatsis2. Patient Dose in Cardiac Radiology. Hellenic J Cardio 2009: 50:17-25. [

[21] Nada A. Ahmed, S. B. Ibraheem a, F. I. Habbani. PATIENT DOSES IN INTERVENTIONAL CARDIOLOGY PROCEDURES IN SUDAN. Doi: 10.1093/ rpd/ncs11 (2012).
[22] Mohamed E. M. Gar-elnabi, Abdoelrahman Hassan. A. B, Abdoelrahman A. Ahmed, Mohamed Yousef. Evaluation of Radiation Dose Received by Patient during Cardiac Catheterization Procedure .IJSR. Value: 6.14, Impact Factor: 438 (2013).

\section{Author Profile}

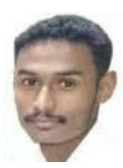

Mr. Abdoelrahman Hassan Ali Bakry (Sudan) received the (B.Sc.) and (M.Sc.) in radiotherapy technology from College of Medical radiological Science, Sudan University of Science and Technology in 2013 and 2015 respectively. During 2013 up to date, he is staying in College of Medical radiological Science, Sudan University of Science and Technology, Radiology Department, Antalya Medical Center and Elnileen Diagnostic Medical Center; also he has been active in Computerized Texture Analysis, Radiotherapy-Oncology, and diagnostic radiology, Medical physics, ultrasound and Nuclear Medicine researches. Now he is assistant teacher at SUST also (2014).

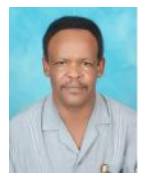

Assoc. proff. Dr. Mohamed Elfadil Mohamed Garelnabi (Sudan) awarded the B. Sc. in Radiotherapy and Nuclear Medicine (1987) and M.Sc. in Radiation Therapy (2000-SUST) and Ph. D. degree in Medical Physics (Natal University-South Africa) in 2007. During 1996-2012 he has been working as lecturer as well as Associate Prof. at SUST department of Radiation therapy. Also he has been active in Computerized Texture Analysis, RadiotherapyOncology, Ultrasound and Nuclear Medicine researches.

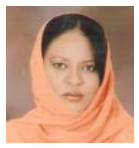

Eitidal H. Khalaf allah, received B.Sc. and M.Sc. in medical physics from Khartoum university faculty of science department of physic, she is a lecturer at Elbyan university of science and technology.

Farouk I. Habbani, Sudan, professor in medical physics, faculty of science university of Khartoum, 